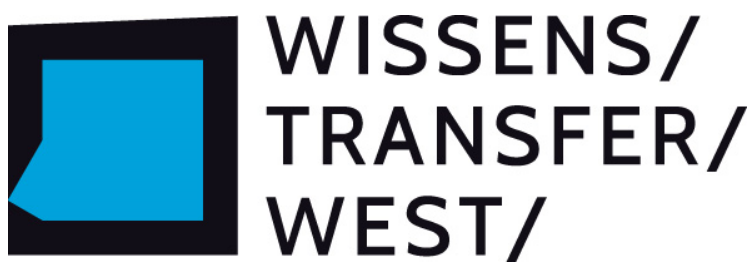

\title{
FAQ Copyright
}

David Lederbauer

\section{https://faq-copyright.uibk.ac.at}

\section{Das Urheberrecht: endlich verständlich}

An Universitäten werden Werke im Sinne des Urheberrechts (beispielsweise Texte, Grafiken und Software) nicht nur täglich verwendet, sondern auch geschaffen. So ist es wenig verwunderlich, dass grundlegende Kenntnisse zum Urheberrecht sowohl für Universitätsmitarbeiter/innen, Forscher/innen als auch Studierende von Bedeutung sind. Da nicht alle davon Jurist/innen sind, sollte die Materie so aufbereitet werden, dass sie auch für Laien verständlich ist. Aus dieser Motivation heraus entstand im Rahmen des Wissenstransferzentrums West die Idee zum FAQ (Frequently Asked Questions) Copyright, einer Datenbank zum österreichischen Urheberrecht, in der Artikel in Form von Fragen und Antworten verfügbar sind. Die Anforderungen an diese Urheberrechtsdatenbank lauteten wie folgt:

- aktuelle Informationen

- $\quad$ niederschwelliger Zugang (für Laien)

- schnell und ortsungebunden abrufbar (online)

- $\quad$ kostenfrei und weiterverwendbar (Creative Commons Lizenz) 
- für alle User/innen zugänglich

- von Expert/innen erstellt und geprüft

\section{Eigentümliche geistige Schöpfung}

Das Konzept der FAQ beinhaltet die Volltextsuche als wichtigstes Instrument zur Navigation. Über Stichworte bzw. Tags sollen die für den/die Leser/in relevanten Inhalte rasch gefunden werden. Daneben ist aber auch eine Suche über bestimmte Themenbereiche (beispielsweise Einführung in das Urheberrecht, Urheberrecht für Lehrende, etc.) oder verlinkte, ähnliche 'Artikel möglich. Die Antwortartikel sind hierbei zweiteilig aufgebaut: in eine kurze und präzise Erstinformation und in eine weiterführende, umfangreichere Detailantwort, die auch Hinweise zu Literatur und Judikatur enthält.

Die aktuelle Datenbank basiert auf der Übernahme der Datenbank des Vereins KB-Law: Copyright, entstanden aus einem FWF Projekt 2006. Diese Datenbank wurde vom Team rund um Assoz. Prof. Mag. Dr. Manfred Büchele vom Institut für Unternehmens- und Steuerrecht der Universität Innsbruck auf den aktuellen Stand von Wissen und Technik überführt. Zudem bekamen die FAQ neben dem neuen Namen auch ein neues Logo sowie ein überarbeitetes Webdesign. Seit der Übernahme wurden etliche existierende Artikel aktualisiert, ergänzt oder von Grund auf neu geschrieben.

Ein großer Vorteil für die Nutzer/innen ist jener, dass die Inhalte selbst der so genannten CC-BY Lizenz unterliegen, welche eine weitgehend freie Nutzung unter Nennung der Autor/innen ermöglicht. Somit können die Informationen leicht in die eigene tägliche Arbeit integriert und auch an Dritte weitergegeben werden. 


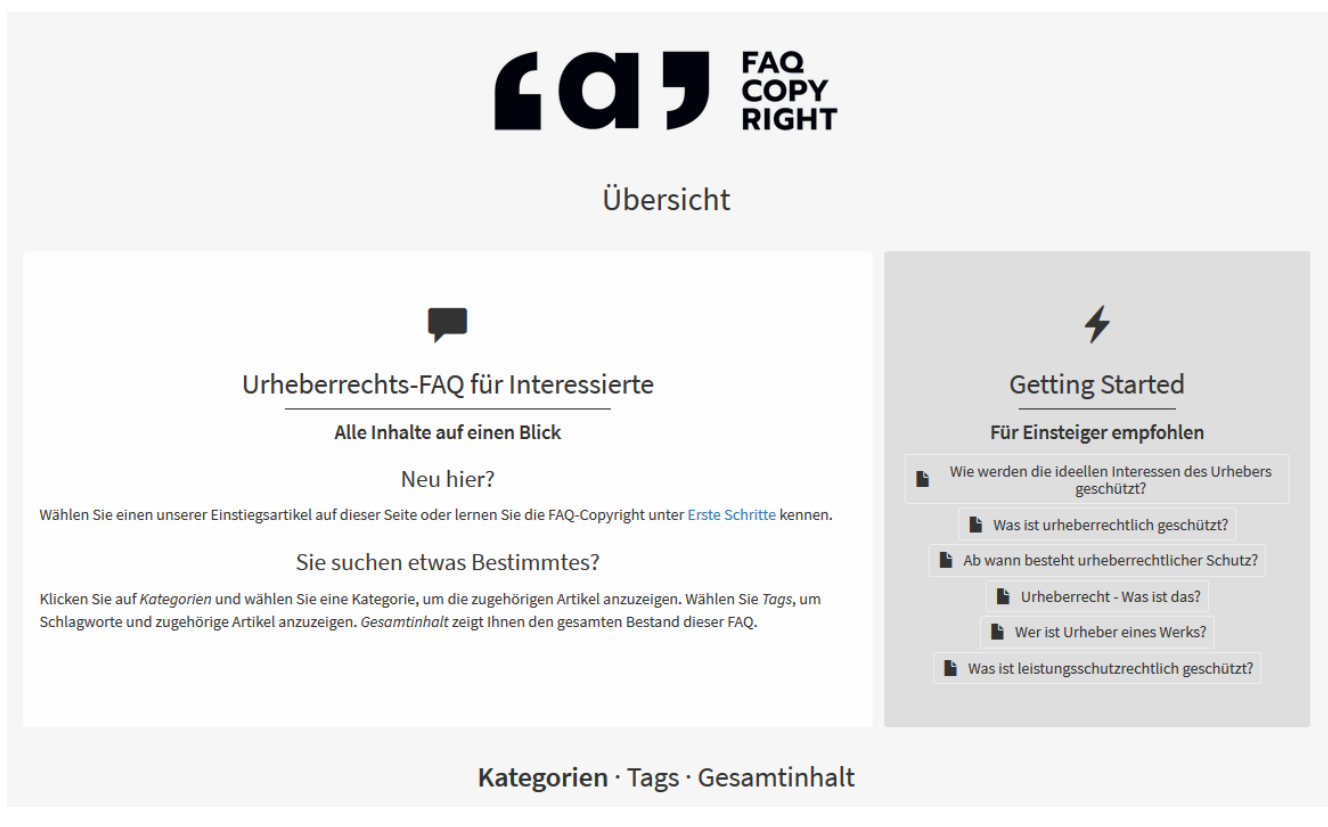

Abbildung 1: Screenshot FAQ Übersicht https://faq-copyright.uibk.ac.at

\section{Quo vadis FAQ?}

In Zukunft soll die "Usability“, also die einfache Handhabung der Website, weiter gesteigert werden. Neben der bereits erwähnten Erneuerung des Webdesigns werden auch laufend neue Inhalte ergänzt. Anhand von Fallbeispielen (Case Studies) soll den User/innen der Praxisbezug der vermittelten Inhalte anschaulich nähergebracht werden. Anregungen, Fragen und Verbesserungsvorschläge der User/innen können jederzeit per Kontaktformular an das Team übermittelt werden. 


\begin{abstract}
Auch nach dem Ende der Finanzierung der Wissenstransferzentren wird die Datenbank FAQ Copyright laufend erweitert werden und einer hoffentlich wachsenden Zahl von Nutzer/innen auch in Zukunft zur Verfügung stehen.
\end{abstract}
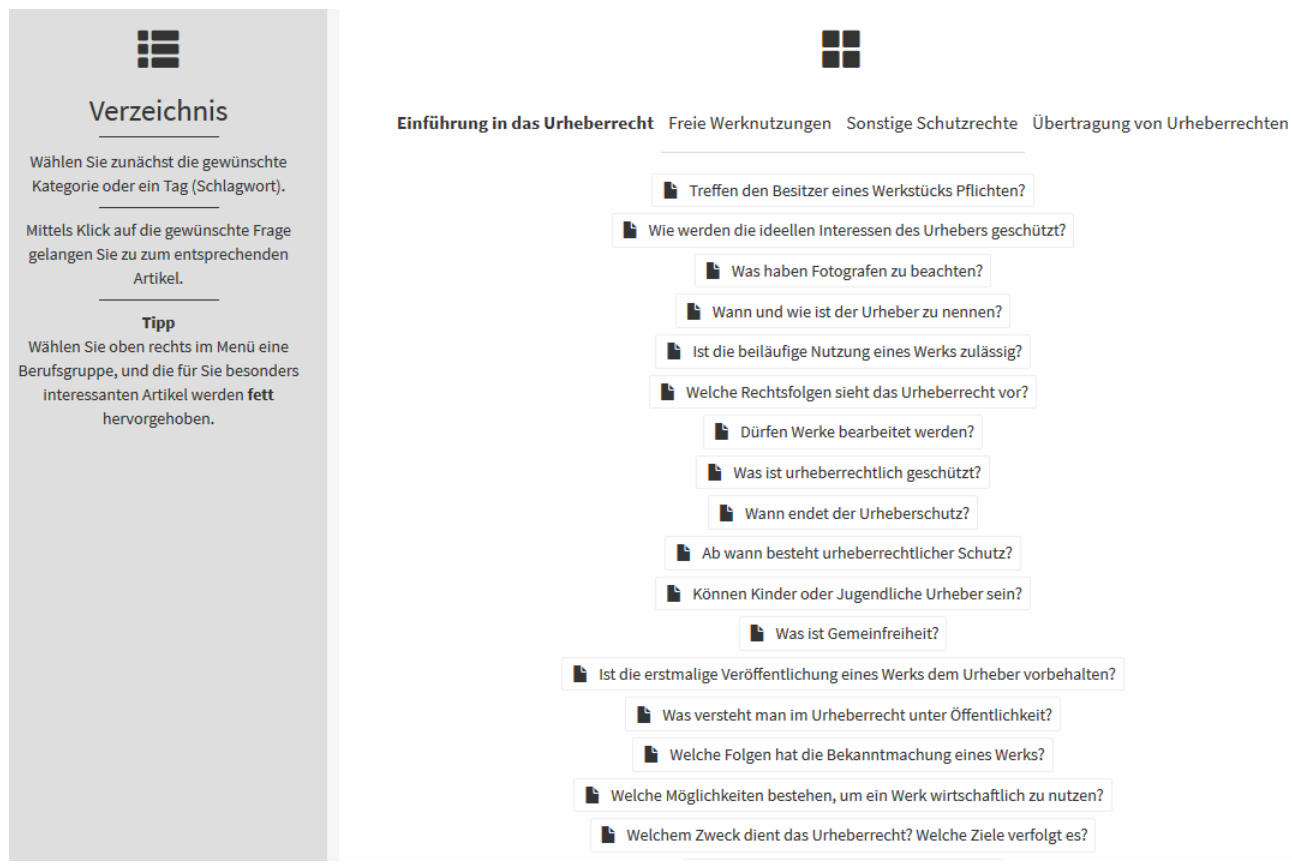

Abbildung 2: Screenshot FAQ Verzeichnis https://faq-copyright.uibk.ac.at 